\title{
Doppler Flow Velocity Indices (RI, PI, S/D \& PSV) of Fetal Middle Cerebral Artery in Normal Pregnancies: Correlation with Gestational Age of 20 to 40 Weeks
}

\author{
TAHER MA ${ }^{\mathrm{a}}$, TASNIM N ${ }^{\mathrm{b}}$, MOHIUDDIN AS $^{\mathrm{c}}$, ALAM MMU ${ }^{\mathrm{d}}$, SHARIF MM ${ }^{\mathrm{e}}$, MANNAN ${ }^{\mathrm{d}}$, GHOS K ${ }^{\mathrm{f}}$
}

\begin{abstract}
:
This observational type of descriptive study was carried out in the Department of Radiology and Imaging, BIRDEM selecting 70 Bangladeshi pregnant babies with the aim to find out the normogram of foetal middle cerebral artery Doppler flow velocity indices and correlation between Doppler flow velocity indices [Resistance Index (RI), Pulsatility Index (PI), Systolic/Diastolic ratio (S/D) \& Peak Systolic Velocity (PSV)] of foetal middle cerebral artery and gestational age in normal pregnancies of 20 to 40 weeks. It was observed that RI, PI and S/D were decreased with the advance of gestational age but PSV was increases with the advance of gestational age. Statistical analyses showed there were significant difference between mean PSV, RI and PI before and after 25 weeks of gestation. No significant difference was found between mean S/D before and after 25 weeks of gestation.
\end{abstract}

\section{Introduction:}

In last 20 years, it is observed that there is an enormous growth in both technical aspects of Doppler ultrasound and its application as one of the popular imaging modalities in the department of radiology and imaging as well as to the physician to assay the condition of blood vessel and flow pattern in various diseases. In addition Doppler ultrasound has an important contribution to make to the surveillance of fetus compromised by Intra Uterine Growth Retardation (IUGR). The advent of color and pulsed Doppler technique has permitted the use of Doppler ultrasound to assess foetal structural abnormalities and complex disease processes involving foetal hemolytic

a. Dr. Md. Abu Taher, MBBS, M.Phil, MD, Associate Professor,

b. Dr. Nuzhat Tasnim, MBBS, M.Phil, Ex M.Phil Student

c. Prof. AS Mohiuddin, MBBS, DMRD, MD, Professor \& Head

d. Dr. Md. Mohit Ul Alam MBBS, Dr. Arifa Mannan, MBBS, M.Phil, Medical Officer,

e. Dr. Md. Mofazzal Sharif, MBBS, MD, Student,

f. Dr. Kona Ghos, MBBS, M.Phil, Ex-Student

Department of Radiology and Imaging, BIRDEM General Hospital, Dhaka.

Address of Correspondence: Dr. Md. Abu Taher, Department of Radiology and Imaging, BIRDEM General Hospital, Dhaka.

Received: 4 January, 2012

Accepted: 21 June 2012
It was observed from Correlation analysis between Doppler indices with independent gestational age that all the Doppler indices of foetal middle cerebra artery was positively correlated with the whole gestation period. The statistical analysis showed only PSV and RI were significantly correlated with the gestational age. Simple regression analysis between dependent Doppler index with independent gestational age before and after 25 weeks revealed that all the Doppler indices had positive relationship with the corresponding gestational age but relationship between PSV and PI (before 25 weeks) with their corresponding gestational ages were only statistically significant.

Key Words: Doppler Indices, Foetal Middle Cerebral artery, Normal pregnancy ranging from 20 - 40 weeks.

(Birdem Med J 2012; 2(2):77-80)

anemia, twin -twin transfusion syndrome and non immune hydrops ${ }^{1}$. For obstetric and fetal purpose arcuate placental vessel of maternal part and uterine artery, aorta, middle cerebral artery, carotid, renal, ductus venosus of foetal part are examined. In experienced hands, waveforms from a number of fetal vessels predict the occurrence and timing of adverse events. Although umbilical arteries are the common vessels assessed by Doppler ultrasonogram, recent studies confirm the efficacy of Middle Cerebral Artery (MCA) Doppler assessment and advocate it. About $80 \%$ blood supply of the brain comes from the middle cerebral artery. Moreover, it has been shown that evaluation of MCA flow velocimetry could provide information about other fetal organs perfusion ${ }^{2}$. So, the MCA has emerged as the vessel of choice in Doppler assessment of fetal intracranial and other organs perfusion, because of its highest resistance indices and earlier presentation of diastolic blood flow, improved ultrasound resolution and advanced pulsed and color coded Doppler Ultrasonogram ${ }^{3,4}$.

Materials and Methods:

This prospective cross sectional study was carried out on consecutively selected 70 subjects who came to the 
Radiology and Imaging department of BIRDEM hospital for doing ultrasonogram of pregnancy profile. The duration of the study was 01 year started from June 2010 to May 2011. The including criterias were normal healthy pregnancy, accurate gestational age; based on last normal menstruation date adapted with ultrasound parameters and normal fetal growth. Histories of the subjects were recorded in a standard questionnaire. Doppler examination of MCA was done on the women placed in a recumbent or semi recumbent position by Siemens, Antars sonoline and Medison sonoace 8000 live (prime) with a convex \& a curvilinear probe of 3.5 $\mathrm{MHz}$. To measure the MCA, an ultrasound scan of the fetal head was performed to obtain a transverse view at the level used usually to measure BPD. The transducer then was moved parallel to this plane towards the base of the skull at the level of the lesser wing of the sphenoid bone to identify the Circle of Willis. After identification of fetal MCA, color flow measure was applied and flow velocity was measured. First PSV and EDV were measured and then PI, RI and S/D were calculated. Congenital abnormalities, oligohydramnios, abnormal fetal biometry with an estimated fetal weight below the $10^{\text {th }}$ percentile or higher than the $90^{\text {th }}$ percentile [cases of intrauterine growth retardation (IUGR) and macrosomia], multiple and twin pregnancies \& autoimmune conditions are excluded. Women with pre- eclampsia, hypertension, abnormal vaginal discharge and bleeding and diabetes mellitus were also excluded. Statistical analysis was done by SPSS (Statistical Package for Social Scientists) programme.

\section{Results:}

It was observed that majority (32.85\%) of the study subjects were from 25-29 years age groups. A few (07.16\%) study subjects were from 35 years above age groups. Mean age of the study subjects was $27(\mathrm{SD} \pm 5)$ years and their age ranged from 19 to 36 years. Regarding PSV it was seen that PSV ranged from $10.50 \mathrm{~cm} / \mathrm{sec}$ to $48.30 \mathrm{~cm} / \mathrm{sec}$ before 25 weeks and mean PSV was 32.17 (SD \pm 7.98$) \mathrm{cm} / \mathrm{sec}$. After 25 weeks PSV was ranged from $20.20 \mathrm{~cm} / \mathrm{sec}$ to $110 \mathrm{~cm} / \mathrm{sec}$ and mean PSV was $64.18 \mathrm{~cm} /$ sec where SD was $30.47 \mathrm{~cm} / \mathrm{sec}$. Mean RI (Mean \pm SD) was $0.76 \pm 0.035$ before 25 weeks and $0.73 \pm 0.087$ after 25 weeks. RI ranged from 0.67 to 0.90 and 0.58 to 0.89 before and after 25 weeks respectively. Regarding PI it was revealed that it ranged from 0.81 to 2.12 before 25 weeks and mean $( \pm S D)$ PI was 1.38( \pm 0.22$)$. After 25 weeks PI was decreased. It then ranged from 1.03 to 2.13 and mean $( \pm S D)$ PI was $1.50 \pm 0.40$. Like RI and PI S/D was also decreased with advance of gestational age. Mean $\mathrm{S} / \mathrm{D}$ was $3.60( \pm 0.60)$ before 25 weeks. It ranged from 2.80 to 6.16 before 25 weeks. After 25 weeks S/D ranged from 2.20 to 8.71 and mean $( \pm \mathrm{SD}) \mathrm{S} / \mathrm{D}$ was $3.98 \pm 2.07$.

Table-I

References ranges of Doppler indices in different weeks of gestation.

\begin{tabular}{lcccc}
\hline Gestational age & \multicolumn{4}{c}{ Doppler Indices } \\
in weeks & PSV (cm/sec) & RI & PI & S/D \\
& mean \pm SD (Max. - Min.) & mean \pm SD (Max. - Min.) & mean \pm SD (Max. - Min.) & mean \pm SD (Max. - Min.) \\
\hline 20 & $19.00 \pm 0.0(0.0-0.0)$ & $0.76 \pm 0.0(0.0-0.0)$ & $1.58 \pm 0.0(0.0-0.0)$ & $4.13 \pm 0.0(0.0-0.0)$ \\
22 & $26.02 \pm 6.64(34.20-16.20)$ & $0.75 \pm 0.019(0.78-0.72)$ & $1.41 \pm 0.14(1.68-1.26)$ & $3.56 \pm .019(3.87-3.28)$ \\
23 & $26.05 \pm 1.98(28.60-23.30)$ & $.075 \pm 0.015(0.78-0.74)$ & $1.37 \pm 0.30(1.44-1.34)$ & $3.65 \pm 0.18(3.90-3.40)$ \\
24 & $29.00 \pm 3.24(33.20-23.30)$ & $0.77 \pm 0.047(0.90-0.73)$ & $1.42 \pm 0.21(2.12-1.33)$ & $3.83 \pm 0.72(6.16-3.30)$ \\
25 & $36.01 \pm 1.73(38.69-33.60)$ & $0.76 \pm 0.027(0.82-0.74)$ & $1.43 \pm 0.083(1.56-1.32)$ & $3.93 \pm 0.78(5.51-3.50)$ \\
26 & $36.88 \pm 13.58(48.30-10.50)$ & $0.74 \pm 0.041(0.79-0.67)$ & $1.49 \pm 0.25(2.0-1.3)$ & $3.45 \pm 0.32(3.8-3.0)$ \\
27 & $42.28 \pm 2.87(45.62-39.25)$ & $0.74 \pm 0.015(0.76-0.72)$ & $1.30 \pm 0.27(1.78-1.15)$ & $3.38 \pm 0.31(3.9-3.1)$ \\
28 & $30.79 \pm 1.25(32.33-28.59)$ & $0.75 \pm 0.27(0.79-0.72)$ & $1.18 \pm 0.048(1.23-1.10)$ & $3.51 \pm 0.31(3.90-3.10)$ \\
29 & $72.18 \pm 18.93(68.0-50.53)$ & $0.70 \pm 0.005(0.71-0.70)$ & $1.22 \pm 0.025(1.25-1.20)$ & $2.76 \pm 0.32(3.0-2.4)$ \\
30 & $61.78 \pm 0.0(86.00-30.58)$ & $0.7 \pm 0.005(0.71-0.70)$ & $1.25 \pm 0.065(1.35-1.20)$ & $2.85 \pm 0.31(3.1-2.4)$ \\
31 & $39.84 \pm 17.46(60.00-29.75)$ & $0.89 \pm 0.0(0.89-0.89)$ & $1.80 \pm .056(2.13-1.15)$ & $4.02 \pm 1.96(6.16-2.3)$ \\
32 & $63.60 \pm 0.0(63.60-63.60)$ & $0.89 \pm 0.0(0.89-0.89)$ & $1.96 \pm 0.0(1.96-1.96)$ & $5.51 \pm 2.50(8.71-3.80)$ \\
33 & $102 \pm 0.0(0.0-0.0)$ & $0.68 \pm 0.00(0.0-0.0)$ & $1.07 \pm 0.00(0.0-0.0)$ & $2.4 \pm 0.00(0.0-0.0)$ \\
35 & $68.50 \pm 40.68(110.0-27.0)$ & $0.62 \pm 0.8(.67-0.58)$ & $1.17 \pm 0.120(1.25-1.00)$ & $2.57 \pm 0.254(2.75-2.39)$ \\
36 & $57.25 \pm 1.29(59.30-56.25)$ & $8.4 \pm 0.04(0.88-0.80)$ & $1.87 \pm 0.02(2.00-1.71)$ & $6.60 \pm 2.30(8.47-2.80)$ \\
37 & $42.78 \pm 0.0(0.0-0.0)$ & $0.82 \pm 0.0(0.0-0.0)$ & $1.63 \pm 0.0(0.0-0.0)$ & $2.9 \pm 0.0(0.0-0.0)$ \\
38 & $58.93 \pm 43.41(108.0-25.50)$ & $0.79 \pm 0.09(0.86-0.69$ & $1.62 \pm 0.51(1.97-1.03)$ & $5.16 \pm 2.52(7.0-2.3)$ \\
39 & $65.61 \pm 48.64(100.0-31.22)$ & $0.74 \pm 0.063(0.79-0.70)$ & $1.33 \pm 0.42(1.63-1.03)$ & $3.45 \pm 1.77(4.71-2.20)$ \\
40 & $120.20 \pm 0.0(0.0-0.0)$ & $0.75 \pm 0.0(0.0-0.0)$ & $1.31 \pm 0.0(0.0-0.0)$ & $3.96 \pm 0.0(0.0-0.0)$ \\
\hline
\end{tabular}

*SD, Maximum and Minimum value 0 indicated that there was only one study subject in that gestational age group. 


\section{Table-II}

Regression analysis between dependent Doppler index with independent gestational age before and after 25 weeks

\begin{tabular}{lcc} 
Doppler Indices & $\begin{array}{c}\text { Statistical test (Regression analysis } \\
\text { between dependent Doppler index with } \\
\text { independent gestational age) } \\
\text { Before 25 weeks }\end{array}$ & $\begin{array}{c}\text { Statistical test (Regression analysis } \\
\text { between dependent Doppler index } \\
\text { with independent gestational age) } \\
\text { After 25 weeks }\end{array}$ \\
\hline PSV & $0.001^{\mathrm{S}}$ & $0.67^{\mathrm{NS}}$ \\
RI & $0.08^{\mathrm{NS}}$ & $0.40^{\mathrm{NS}}$ \\
PI & $0.03^{\mathrm{S}}$ & $0.56^{\mathrm{NS}}$ \\
S/D & $0.08^{\mathrm{NS}}$ & $0.10^{\mathrm{NS}}$ \\
\hline
\end{tabular}

\section{Table III}

\begin{tabular}{|c|c|c|}
\hline \multicolumn{3}{|c|}{ Correlation analysis between Doppler indices with independent gestational age } \\
\hline Doppler Indices & r-value & $\begin{array}{c}\text { Statistical test } \\
\text { (Correlation analysis between } \\
\text { Doppler index with gestational age) }\end{array}$ \\
\hline$\overline{\mathrm{PSV}}$ & 0.54 & $0.001^{\mathrm{S}}$ \\
\hline RI & 0.75 & $0.03^{\mathrm{S}}$ \\
\hline PI & 0.48 & $0.09^{\mathrm{NS}}$ \\
\hline $\mathrm{S} / \mathrm{D}$ & 0.12 & $0.28^{\mathrm{NS}}$ \\
\hline
\end{tabular}

* S=Significant, NS= Not significant, $\mathrm{p}<0.05$ was considered as significant. Unit of PSV was $\mathrm{cm} / \mathrm{sec}$. Rest of the indices did not have any unit. PSV= Peak Systolic Velocity, RI= Resistance Index, PI= Pulsatility Index, S/D= Systolic/Diastolic ratio.

\section{Discussion:}

In this study it was observed that majority (32.85\%) of the study subjects were from 25-29 years age groups and mean age of the study subjects was $27(\mathrm{SD} \pm 5)$ years and their age ranged from 19 to 36 years. This age distribution reflects the age related fertility of the study subjects. Considering the age of viability as 25 weeks ${ }^{5}$ the Doppler indices observations are categorized in two groups (less than 25 weeks groups and more than 25 . weeks). Regarding PSV it was seen that mean $( \pm \mathrm{SD})$ PSV was $32.17( \pm 7.98) \mathrm{cm} / \mathrm{sec}$. After 28 weeks PSV was mean PSV was $64.18 \mathrm{~cm} / \mathrm{sec}$ where SD was $30.47 \mathrm{~cm} /$ sec. This increase in PSV with the increase of gestational age is consistent with the study conducted by Bahlmann et $a .^{2}$ and Ebrashy et $a l .{ }^{6}$ demonstrated a continuous increase of MCA PSV over the period from 18 to 40 and 19 to 41 weeks of gestation. This indicated the progressive increased vascular resistance of foetal middle cerebral artery. There was similarity in statistical analyses revealed there were significant difference between mean PSV before and after 25 weeks of gestation and PSV in positively correlated with gestational age. RI (Expressed as Mean \pm SD) was $0.76 \pm 0.035$ before 28 weeks and $0.73 \pm 0.087$ after 28 weeks. The decrease in RI (Mean) was 0.8 in 28 weeks and in 42 weeks RI (Mean) was 0.61 in the study carried out by Bahlmann et $\mathrm{al}^{2}$. Regarding PI it was found that it ranged from 1.03 to 2.13 before 25 weeks and mean $( \pm$ SD) PI was $1.50( \pm 0.40)$. After 25 weeks PI was decreased. It then ranged from 0.81 to 2.12 and mean $( \pm S D)$ PI was $1.38 \pm 0.22$. Kassanos et al. ${ }^{7}$ observed the MCA PI decrease as gestational age advanced from 20 weeks [1.97 (SD 0.48)] to 37 weeks [1.15 (SD 0.18)]. Statistical analyses was similar between the present study and the study carried out by Kassanos et al. ${ }^{7}$ where it was revealed there were significant difference between mean PSV before and after 25 weeks of gestation and PSV was positively correlated with gestational age. The fall in the fetal MCA PI after 25th week of gestation was probably reflected a decreasing vascular resistance with increasing gestational age or correlation with deoxyribonucleic acid production in fetal brain. Like the study conducted by Manning et $a l^{4}$. and 
Sunsaneevithayakul et al. ${ }^{8}$ S/D $[3.60( \pm 0.60)$ before 25 weeks and mean $3.98 \pm 2.07$ after 25 weeks] was decreased with advance of gestational age. The principal reason for this was decreasing blood flow resistance with increasing of gestational age especially at the end of pregnancy that accompanying by blood flow volume increasing. Statistical analysis showed no significant difference between mean S/D before and after 25 weeks of gestation. But this statistical analysis was not similar with the study carried out by Manning et $a l^{4}$. and Sunsaneevithayakul et al. ${ }^{8}$

\section{Conclusion:}

From this study it could be concluded that RI, PI and S/ D were decreased with the advance of gestational age but PSV was increases with the advance of gestational age. Statistical analyses revealed that there were significant difference between mean PSV, RI and PI before and after 25 weeks of gestation. No significant difference was found between mean S/D before and after 25 weeks of gestation. It was observed from Correlation analysis between Doppler indices with independent gestational age that all the Doppler indices of foetal middle cerebra artery was positively correlate with the whole gestation period. Simple regression analysis between dependent Doppler index with independent gestational age before and after 25 weeks revealed that all the Doppler indices had positive relationship with the corresponding gestational age but relationship between PSV and PI (before 25 weeks) with their corresponding gestational ages were only statistically significant.

\section{References:}

1. Tarzamni MK, Sobhani NNN, Eshraghi N, Tarzamni M, Talebi Y. Nomograms of Iranian fetal middle cerebral artery Doppler waveforms and uniformity of their pattern with other populations' nomograms. BMC Pregnancy and Childbirth 2008; 8; 50-62.

2. Bahlmann F, Reinhard I, Krummenauer F, Neubert S, Macchiella D, Wellek S. 'Blood flow velocity waveforms of the fetal middle cerebral artery in a normal population: reference values from 18 weeks to 42 weeks of gestation'. J Perinat Med 2002; 304; 90-501.

3. Mari G, Adrignolo A, Abuhamad AZ, Pirhonen J, Jones DC, Ludomirsky A, et al. Diagnosis of fetal anemia with Doppler ultrasound in the pregnancy complicated by maternal blood group immunization. Ultrasound Obstet Gynecol 1995; 5; 400-405.

4. Manning FA, Morrison I, Harman CR, Lange IR and Menticoglou S. Fetal assessment based on fetal biophysical profile scoring: Experience in 19221 referred high-risk pregnancies. Am J Obstet Gynecol 1987; 157; 880-84.

5. Seri I and Evans J. Limits of viability: definition of the gray zone. Journal of Perinatology 2008; 28; 4-8.

6. Ebrashy A, Azmy O, Ibrahim M, Waly M and Edris A. Middle Cerebral/ Umbilical Artery Resistance Index Ratio as Sensitive Parameter for Fetal Well-being and Neonatal Outcome in Patients with Preeclampsia: Case-control Study. Croat Med J 2005; 46; 821-25.

7. Kassanos D, Siristatidis C, Vitoratos N, Salamalekis E, Creatsas G. The clinical significance of Doppler findings in fetal middle cerebral artery during labor. J Obstet Gynecol Reprod Bio 2007; 109; 45-50.

8. Sunsaneevithayakul P, Siwadune T, Boriboonhirunsarn D, Titapant V, Sutuntavibul A. Reference centile charts for fetal umbilical artery Doppler velocimetry waveform of Thai fetuses, Thai J Obstet Gynaecol 2000; 12; 201-11. 